\title{
CDISC SDTM FDA Technical Specification Response Terminology
}

National Cancer Institute

\section{Source}

National Cancer Institute. CDISC SDTM FDA Technical Specification Response

Terminology. NCl Thesaurus. Code C160926.

Terminology associated with the FDA technical specification response codelist of the Clinical Data Interchange Standards Consortium (CDISC) Study Data Tabulation Model (SDTM). 